\title{
Modelling and Control of a Single-Wheel Inverted Pendulum by Using Adams and Matlab
}

\author{
Sinan İlgen ${ }^{1}$, Emre Oflaz ${ }^{1}$, Erdi Gülbahçe ${ }^{1}$, Abdullah Çakan*² \\ Accepted $3^{\text {rd }}$ September 2016
}

\begin{abstract}
This research is aimed at developing a multi-body simulation model and balancing control of a single-wheeled inverted pendulum. A virtual prototype of the system has been built by using Adams software and it is simulated in both Matlab and Adams software together. The Adams model has two inputs (disturbance and control) and two outputs (pendulum angle and wheel position). Proportional-integral-derivative (PID) controller is designed and applied for balancing control and simulation of pendulum angle. The modelling and control results show that the Proportional-integral-derivative (PID) controller can successfully achieve balancing control of the single-wheeled inverted pendulum. Also this paper can make an important contribution to background of two-wheeled robots, selfbalancing transportation devices.
\end{abstract}

Keywords: PID Control, Modelling, Simulation, Self-balancing, Single-wheel inverted pendulum.

\section{Introduction}

During the recent years, robots have become a basic and timehonoured practice for proving a variety of control systems and control theories. Thanks to their flexible and basic structures, two wheeled self-balancing robots perform well in poor work conditions and complex tasks (space explorations, topographical survey, dangerous goods transportation etc.). Also they can provide safe transportation for both goods and persons thanks to high mobility and rapid response abilities [1].

One and two wheeled self-balancing robots have been started to be seen in literature by 2000 s and became more popular nowadays. Due to the fact that they have characteristics as multiple variability, nonlinearity, and instability, they have chosen as an important field of study by researchers working on control theory. Stability, durability, and controllability of a system can be easily examined with one-wheeled self-balancing robots [2-3].

One-wheeled self-balancing systems are consisting of a mobile robot and an inverted pendulum system. Since it is driven with two coaxial and independently controllable motors, movement of the system is not stable. In order to sense the acceleration along the vertical axis, gyroscope and accelerometer are used in this kind of systems. In order to make the inverted pendulum stable both when it is on the move and steady, torque signals are generated and transmitted to motors [4-5].

Park and Jung designed a single-wheel mobile robot called GYROBO. They used remote control and sensors in order to both navigate and balance the robot. With PD controller and sensors (gyro, tilt and encoder), GYROBO was able to balance itself and follow the specified trajectory [6]. Cieslak et al. designed and

${ }^{I}$ Department of Mechatronics Engineering, Faculty of Engineering, KTO Karatay University, Konya-Turkey

${ }^{2}$ Department of Mechanical Engineering, Faculty of Engineering,

Selçuk University, Konya-Turkey

* Corresponding Author: Email: acakan@selcuk.edu.tr

Note: This paper has been presented at the $3^{\text {rd }}$ International Conference on Advanced Technology \& Sciences (ICAT'16) held in Konya (Turkey), September 01-03, 2016. built a one-wheel robot. They mainly focused on self-stabilisation problem and achieved the dynamic stability [7]. Lee at al. designed a single-wheel inverted pendulum system. The system consisted of a dc motor and two ducked fans. Pitch angle of system was controlled by dc motor and PD controller. Roll angle was regulated by PID controller and air pressure generated from fans [8]. In his study, Wang applied PID controller to stabilization control of different types of inverted pendulum. Study shows that PID controllers are very effective in this kind of systems [9]. There are similar studies which are conducted on two-wheel systems. Felix et al. designed a two-wheel selfbalancing robot called JOE. In order to control this robot, they designed two independent space state models and made the system stand in balance successfully [10]. Wei and Yangmin Li designed PID controller and Linear Quadratic Regulator (LQR) controller and the system was simulated in Matlab, then these two controller methods were applied and results were compared [11]. Kalyoncu et al designed artificial neural network and fuzzy logic based $(\mathrm{ANN}+\mathrm{FL})$ controller in order to control a two-wheeled robot. After that system was simulated in Matlab/Simulink and results were compared [12].

This paper presents developing a multi-body simulation and control of a inverted pendulum. An approximation model of the system is modelled by using Adams software. The Adams model has two inputs (disturbance and control) and two outputs (pendulum angle and wheel position) respectively. Pendulum angle which is the most important parameter needs to be controlled issued as feedback. Proportional-integral-derivative (PID) controller is designed and implemented for balancing control of pendulum angle. Controller design procedure and controller efficiency are shown with graphics. One can understand that single-wheel inverted pendulum system can be simulated and controlled in Adams and Matlab.

\section{Modelling and Control}

Modelling and controlling strategy and system model can be seen in Fig 1. To obtain the dynamic model of single-wheeled inverted pendulum, Adams software is used. Boundary conditions and 
dynamic loadings are performed in Adams. Thus, more realistic model is derived. Besides this, it is very important to Adams cooperate with Matlab.
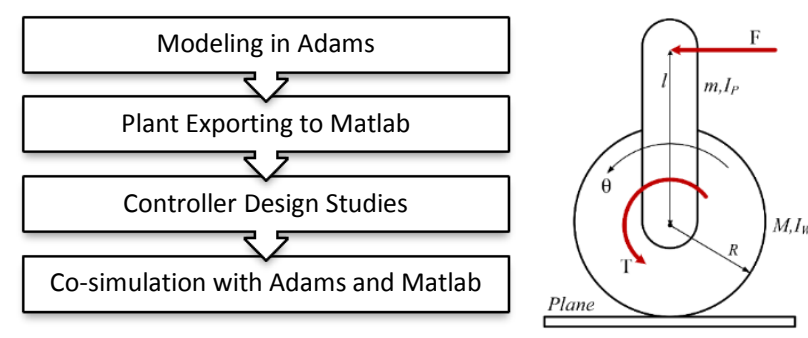

Figure 1. Strategy of study and system model

Single-wheeled inverted pendulum is able to move in only $\mathrm{x}$ direction. Inverted pendulum system is firstly modelled in Adams. System has two inputs (control and disturbance) and two outputs (pendulum angle and wheel position). Necessary boundary conditions like as connections, friction and movement etc. are defined in Adams. System parameters and boundary conditions can be seen in Table 1. Then, designed system is exported to Matlab in order to perform controller design works in this software.

Table 1. Properties of pendulum and wheel

\begin{tabular}{cll}
\hline $\mathbf{M}$ & Mass of the wheel & $0.153 \mathrm{~kg}$ \\
$\mathbf{m}$ & Mass of the pendulum & $0.2 \mathrm{~kg}$ \\
$\mathbf{I}$ & Pendulum length & $0.12 \mathrm{~m}$ \\
$\mathbf{I}_{\mathbf{P}}$ & Pendulum mass moment of inertia & $1.3 \times 10^{-2} \mathrm{~kg} \cdot \mathrm{m}^{2}$ \\
$\mathbf{I}_{\mathbf{W}}$ & Wheel mass moment of inertia & $1.85 \times 10^{-3} \mathrm{~kg} \cdot \mathrm{m}^{2}$ \\
$\mathbf{R}$ & Wheel radius & $0.05 \mathrm{~m}$ \\
$\mathbf{T}$ & Torque applied to the wheel & N.m \\
$\boldsymbol{\theta}$ & Pendulum angle & degree \\
$\mu_{\mathbf{S}}$ & Static columb friction & 0.8 \\
$\mu_{\mathbf{D}}$ & Dynamic columb friction & 0.3 \\
\hline
\end{tabular}

General block diagram including system modelling and controller design can be seen in Fig 2. System is a multiple input - multiple output (MIMO) structure which consist of two inputs and two outputs. Inputs are defined as controller (torque, N.m) and disturbance (force, N). Similarly, outputs are defined as pendulum angle (deg) and wheel position (m). Here, pendulum angle which is the most important parameter needs to be controlled issued as feedback. Wheel position is analysed in order to view only motion trajectory.

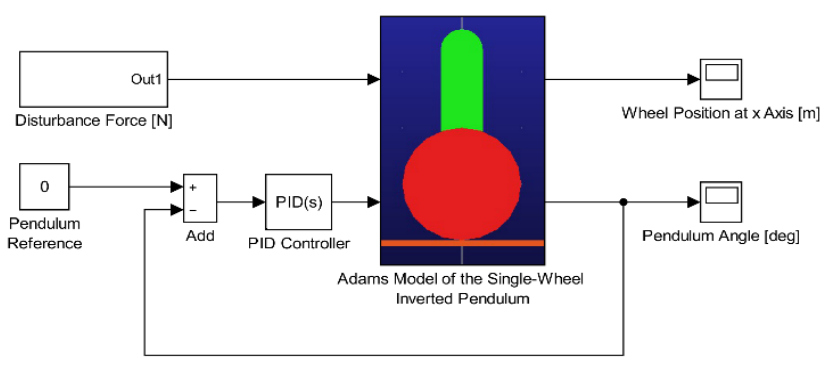

Figure 2. Block diagram of the system

Time, direction and magnitude of disturbance force is determined and applied to top of the pendulum. $10 \mathrm{~N}$ impulse force is applied to pendulum in 1 st second of simulation time through $-\mathrm{x}$ direction and then another $10 \mathrm{~N}$ impulse force is applied in 3rd second of simulation time through the opposite direction. The controller is always active during simulation period. Signal applied as disturbance can be seen in Fig 3 .

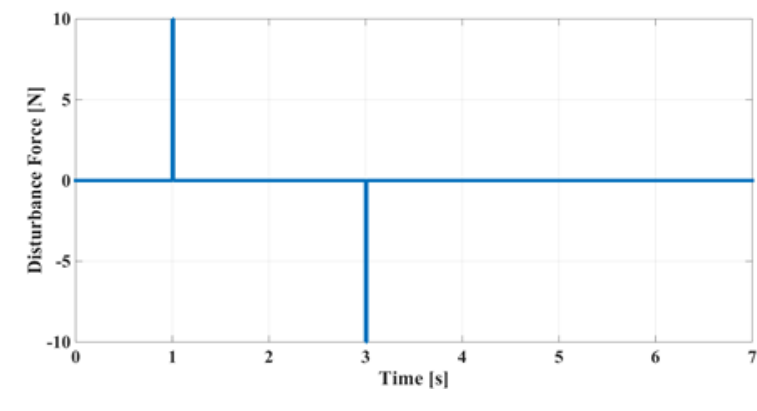

Figure 3. Disturbance signal

\section{Results and Discussion}

Uncontrolled and controlled responses of the system are analysed after PID controller is designed. Uncontrolled pendulum angle and wheel position responses of the system under the disturbance force can be seen in Fig 4 and Fig 5. As seen in Fig 4, uncontrolled pendulum angle has oscillation under the disturbance force. However the displacement of wheel position is very low since there is friction between wheel and ground. Same result is seen in Adams simulation, also.

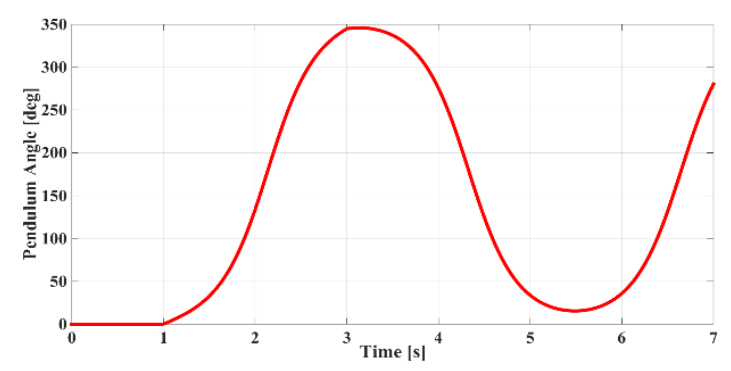

Figure 4. Pendulum angle of uncontrolled system

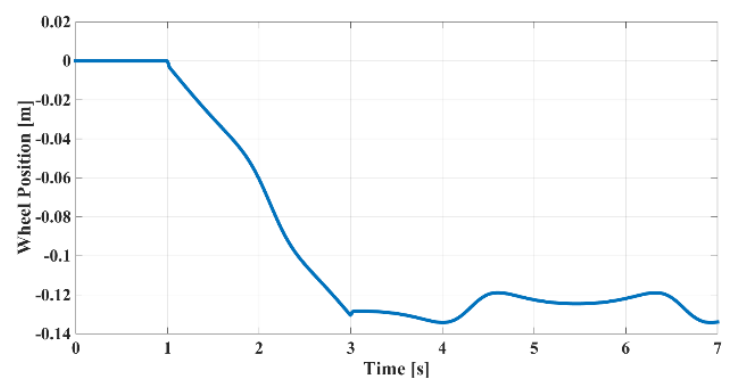

Figure 5. Wheel position of uncontrolled system

Then, controlled system responses and simulation studies are analysed. Since system is nonlinear, PID coefficients are obtained by trial and error method. After trials, gains were defined as $\mathrm{Kp}=-$ $4, \mathrm{Ki}=-0.02$, and $\mathrm{Kd}=-2.5$ for this study. Pendulum angle and wheel position responses of the system with PID controller can be seen in Fig 6 and Fig 7. 


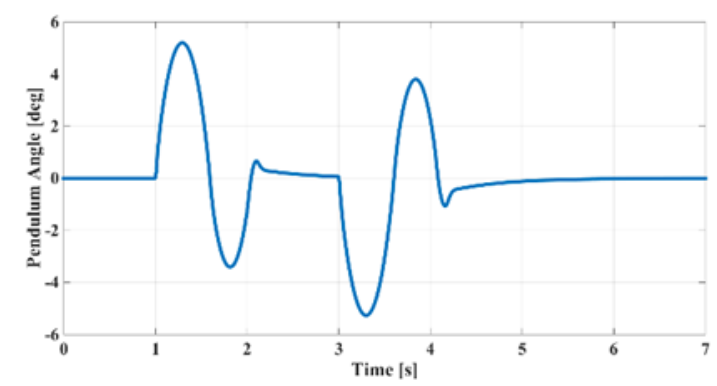

Figure 6. Pendulum angle of controlled system

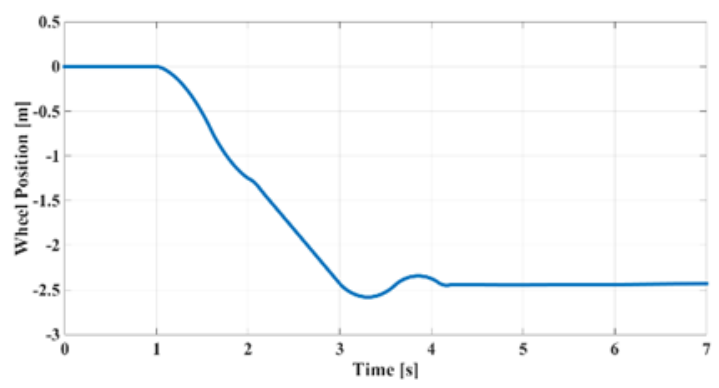

Figure 7. Wheel position of controlled system

In order to make the system stable, necessary torque driven by controller can be seen in Fig 8 .

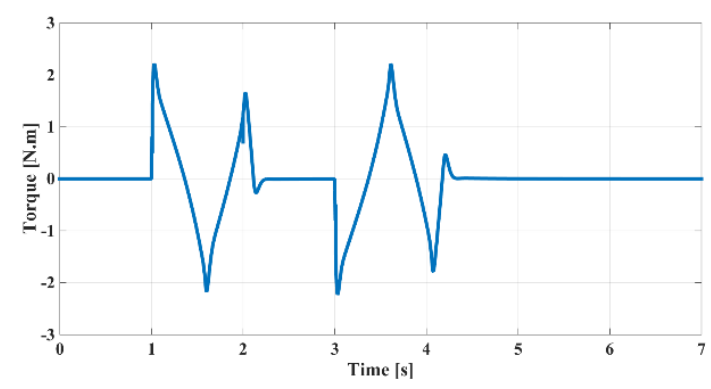

Figure 8. Controller response (torque requirement)

\section{Conclusion}

There is a lack of knowledge in simulating and controlling the one or more wheel inverted pendulum systems with Adams and Matlab. In this paper, it is shown that single-wheel inverted pendulum system can be simulated and controlled in Adams and Matlab. Also, for future works, this study forms a basis for simulation and control of one or more wheel self-balancing systems.

These kinds of systems have nonlinear characteristics. Efficiency of the software solutions is very important in developing realistic approaches to such kind of systems. In this study, it is shown that Matlab and Adams are efficient in simulating and controlling the nonlinear systems like inverted pendulums.

In this study, pendulum angle of a single-wheel inverted pendulum system is controlled under necessary boundary conditions. Controller design procedure and controller efficiency are shown with graphics. Also, necessary torque values are given in graphics. In this way, design parameters and required equipments for future works and experimental studies are determined.

\section{References}

[1] J. Wu and W. Zhang, Design of Fuzzy Logic Controller for Two-wheeled Self-balancing Robot, 2011 6th International Forum on Strategic Technology, IFOST 2011, Harbin, China, August 2011.

[2] J. Wu and W. Zhang, Research on Control Method of Twowheeled Self-balancing Robot, 2011 4th International Conference on Intelligent Computation Technology and Automation, ICICTA 2011, Shenzhen, China, March 2011, vol.1, pp.476-479.

[3] M.A. Şen and M. Kalyoncu, İki Tekerlekli Kendi Kendini Dengeleyen Robotun Yörünge Takibi için Arı Algoritması kullanarak LQR Kontrolcü Tasarımı, Uluslararası Katılımlı 17. Makina Teorisi Sempozyumu, İzmir, 14-17 Haziran 2015.

[4] University of Michigan Control Tutorials for MATLAB and Simulink (CTMS) Website. [Online]. Available: $\mathrm{http} / / / \mathrm{ctms}$.engin.umich.edu/CTMS/index.php?example=In vertedPendulum\&section=SystemModeling

[5] K.H. Lundberg and T.W. Barton, History of Inverted Pendulum Systems, 8th IFAC Symposium on Advances in Control Education vol. 42, pp 131-135, 2010.

[6] J.H. Park and S. Jung, "Development and control of a single-wheel robot: Practical Mechatronics approach," Mechatronics vol. 23 , pp. 594-606, 2013

[7] P. Cieslak, T. Buratowski, T. Uhl, and M. Giergel, "The mono-wheel robot with dynamic stabilisation," Robotics and Autonomous Systems, vol. 59, pp 611-619, Sep. 2011.

[8] J.H. Lee, H.J. Shin, S.J. Lee, and S. Jung, "Balancing control of a single-wheel inverted pendulum system using air blowers: Evolution of Mechatronics capstone design," Mechatronics, vol. 23, pp. 926-932, 2013.

[9] J.J. Wang, "Simulation studies of inverted pendulum based on PID controllers," Simulation Modelling Practice and Theory, vol. 19, pp. 440-449, 2011.

[10] F. Grasser, A. D'Arrigo, S. Colombi, and A.C. Rufer, "JOE: a mobile, inverted pendulum," IEEE Transactions on Industrial Electronics, vol. 49, pp. 107-114, 2002.

[11] W. An and Y. Li, Simulation and Control of a Twowheeled Self-balancing Robot, IEEE International Conference on Robotics and Biomimetics (ROBIO), Shenzhen, China, pp. 456-461, Dec. 2013.

[12] M. Kalyoncu, M.A. Şen, and M. Tinkir, İki Tekerlekli Kendini Dengeleyebilen Bir Araç İçin Yapay Sinir Ağ1 ve Bulanık Mantık Tabanlı Kontrolcü Tasarımı, Otomatik Kontrol Ulusal Toplantıs1-(TOK 2014), Otomatik Kontrol Ulusal Toplantıs1 Bildiriler Kitab1, pp. 682-687, Kocaeli, 11-13 Eylül 2014. 